\title{
ANTI-HEPATOTOXIC AND SYNERGISTIC EFFECTS OF SESAME OIL WITH METHOTREXATE IN ADJUVANT- INDUCED ARTHRITIS
}

\author{
Zeinab Y. Ali1, HananAbdelmawgoud Atia2, Raouf M. El Allawy1 \\ and Shaimaa M. Abd Alla \\ BIOCHEMISTRY DEPARTMENT,NATIONAL ORGANIZATION \\ FOR DRUG CONTROL AND RESEARCH1 andFACULTY OF \\ PHARMACY (GIRLS), AL AZHAR UNIVERSITY2
}

Received 4/3/2017 - Accepted 23/5/2017

\begin{abstract}
Methotrexate (MTX) is the first-line agent for rheumatoid arthritis (RA) treatment although it causes hepatotoxicity leading to poor compliance to therapy. Sesame oil is unique due to its unusually high oxidative stability and anti-inflammatory property that attributed mainly to the presence of $\alpha$-tocopherol and anti-oxidative sesame lignans. These components give sesame oil extraordinary high oxidative stability and anti-inflammatory property. The present study aimed to investigate the anti-hepatotoxic and therapeutic potential of sesame oil alone or in combined therapy with MTX on RA rat model. Assessment of RA performed by measuring paw volume, rheumatoid factor and anti-cycliccitrullinated peptide antibody. Biomarkers of cartilage degeneration (MMP-3) and synthesis, (IGF-1), inflammatory mediators (TNF- $\alpha$, IL-6, NO), anti-inflammatory mediators(IL-10) and oxidative stress were estimated. MTX mono-therapy were enhanced hepatotoxicity but concomitant administration with sesame oil was able to ameliorating RA biomarker and led to an increase its effectiveness without hepatotoxicity. Therefore combined therapy of MTX with sesame oil may lead to synergistic anti-arthritic action with fewer side effects of MTX on liver.
\end{abstract}

Key words: Rheumatoid arthritis; Methotrexate; Hepatotoxicity; Sesame oil.

* Correspondence Author (e mail: Zeina6 X. Ali@hotmail.com) 


\section{INTRODUCTION}

Rheumatoid arthritis (RA) is a systemic chronic progressive inflammatory autoimmune disorder that can be developed in any age and affects joints. RA features are characteristic by continuous inflammation, hyperplasia in synovium and cartilage erosion. Furthermore, RA is accompanied by joint swelling and destruction. However, the early treatment can prevent severe disability and improve patient quality of life, the most problem a considerable number of patients meet is lacking of an effective treatment (CastroVillegaset al., 2015).

Methotrexate (MTX), antirheumatic drug (disease-modifying agent) is recommended as the first-line evidence-based therapy for recently diagnosed RA patients as it works as immunosuppressive agent (Singh et al., 2016a). MTX efficacy in the treatment of RA is supported by evidence, leading to improved short-term control of the disease and long-term outcomes by decreasing radiographic progression (Sharma_and Scott, 2015). However, it is associated with hepatotoxicity. There are several mechanisms are concerned with liver cell damage initiation and propagation.Dysfunction in this cell causes disequilibrium in homeostatic condition, thus resulting in intracellular oxidative stress with increasing in reactive oxygen species formation. Methotrexate-induced hepatotoxicity is common however its actual frequency is difficult to determine due to underreporting, difficulties in diagnosis, and incomplete observation of exposure (Singh et al., 2016b).

Due to these undesirable effects, up to $12 \%$ of RA patients discontinue methotrexate after six months to two years of treatment (Maja et al, 2013). Therefore, new drugs are seriously needed for more effectiveness and fewer side effects. Many plants and compounds derived from them are used in conventional medicine might be useful in alleviating inflammation and inflammatory pain $(\boldsymbol{X} \boldsymbol{u}$ et $a l$. ,, 2014). Sesame oil is derived from the plant species SesamumindicumL., an herbaceous annual belonging to the Pedaliaceae family(Monteiro et al., 2014).Sesame seed contains up to sixty percent oil of a very high quality (Ayana, 2015). Sesame oil has been proved to possess broad-spectrum pharmacological effects including anti-mutagenic, anti-oxidant, anti-atherosclerotic, anti- 
inflammatory and anti-pyretic protective effects (Monteiro et al., 2014; Narasimhulu et al., 2015; Vasiljevic et al., 2016).

The present study aimed to investigate the anti-hepatotoxic and therapeutic potential of sesame oil alone or in combined therapy with MTX on RA rat model.

\section{MATERIALS AND METHODS}

Sesame seed were procured from National Organization for Drug Control and Research (NODCAR) and converted into oil by cold pressed by especial machine.Methotrexate injection $50 \mathrm{mg}$ was used for treatment of RA that manufactured for ACDIMA international by: Shanxi powerdone pharmaceutical co., Ltd. Complete Freund's adjuvant (CFA) was used for induction of RA (Sigma-Aldrich, St. Louis, MO, USA). Methotrexate (MTX) was used at two different doses once a week ( $1 \mathrm{mg} / \mathrm{Kg}$ b.wt and $2 \mathrm{mg} / \mathrm{Kg}$ b.wt, respectively) is equivalent to human sub- therapeutic and therapeutic doses (Banji et al., 2011). The freshly prepared sesame oil was evaluated in normal and arthritic rats at a dose of $1 \mathrm{ml} / \mathrm{kg}$ (Sotnikova et al, 2009).

A total of 84 adult female albino Sprague-Daley rats weighing150$180 \mathrm{~g}$ were housed under standard conditions. The animals were acclimatized to the new atmosphere for a week prior to the experiment. Arthritis was induced by injection of $0.1 \mathrm{ml} / \mathrm{rat}$ of CFAto anaesthetized animals in the sub plantar tissue of the right posterior paw. This injection produced definite edema within $24 \mathrm{~h}$ with progressive arthritis by day 9 after injection (Borashan et al., 2009).Treatments were started from day 10 and continued up to day 45.

The rats were divided equally into seven groups as following:Group 1: Control ratswas injected i.p with saline daily for 45 days.Group 2: Arthritic rats without treatment,Group 3: After 10 days, arthritic rats were injected with MTX (1mg/kg once a week for five weeks) by i.p route (M1). Group 4: Arthritic rats were injected with MTX (2 mg/kg once a week for five weeks) by i.p route (M2). Group 5: Arthritic rats were received daily oral dose of sesame oil $(1 \mathrm{ml} / \mathrm{kg}$ for five weeks)(S.O). Group 6:Arthritic rats were injected with MTX $(1 \mathrm{mg} / \mathrm{kg}$ once a week for five weeks) and received daily $(1 \mathrm{mg} / \mathrm{kg})$ sesame oil for 5 weeks by oral route(S.O+M1).Group 7:Arthritic rats were injected with MTX (2 mg/kg once a week for five weeks) and 
received daily $(1 \mathrm{mg} / \mathrm{kg})$ sesame oil for 5 weeks by oral route(S.O+M2).

Swelling of hind paw was estimated with a plethysmograph. On the $46^{\text {th }}$ day, rats were anaesthetized by administration of enflurane and blood samples were withdrawn from the retro orbital plexus. Serum was separated for estimation of: Anti-cyclic citrullinated peptide antibody (Anti-CCP) by ELISA kit according to Bizzaro et al., (2001), Rheumatoid factor (RF)by ELISA kit according to Ernst et al., (1988), Nitric oxide(NO)by colorimetric method according to Montgomery and Dymock, (1961).Tumor necrosis factor- $\alpha$ (TNF$\alpha$ ), Interleukin-6 (IL-6), Interleukin-10 (IL-10),Matrix metalloproteinase-3 (MMP-3), Insulin-like growth factor-1 (IGF1)were measured by ELISA kits according to the manufacturer's instructions.Transaminases (AST\&ALT) were measured by colorimetric method according toReitman and Frankel, (1957). Alkaline phosphatase (ALP)was measured by colorimetric method according toBelfield and Goldberg (1971). ${ }^{\gamma}-$ Glutamyltransferase(GGT)was measured by colorimetric method (Heersink et al., 1980).Total Bilirubin(T.B)was measured by colorimetric method(Water and Gerade 1970). Total protein (T.P)was measured by colorimetric method (Gornal et al., 1949). Total antioxidant capacity (TAC)was measuredby colorimetric method (Koracevicet al., 2001). Malondialdehyde (MDA) was measured by colorimetric method (Ohkawa et al., 1979) andReduced glutathione(GSH) was measured by colorimetric method (Beutler et al., 1963).

Statistical analysis: The biochemicalresults were expressed as mean \pm standard error (S.E). Results were statistically analyzed by one- way analysis of variance ANOVA Statistical Package for the Social Sciences (SPSS) version 21 followed by Duncan Multiple Comparison test $(\mathrm{DMCT}) \mathrm{P}<0.05$ was considered significant.

\section{RESULTS}

The volume of paw oedema was markedly reduced in treated groups $(\mathrm{M} 1: 2.08 \pm 0.21, \mathrm{M} 2: 1.22 \pm 0.21$, S.O:1.62 \pm 0.14,S.O+M1: $0.72 \pm 0.14, \mathrm{~S} . \mathrm{O}+\mathrm{M} 2: 0.57 \pm 0.05)$ as compared to RA group $(4.65 \pm$ $0.64)$. The paw edema was significantly reduced with therapy in the 
following order: $\mathrm{S} . \mathrm{O}+\mathrm{M} 2>\mathrm{S} . \mathrm{O}+\mathrm{M} 1>\mathrm{M} 2>\mathrm{S} . \mathrm{O}>\mathrm{M} 1$. Anti-CCP and RF levels were significantly elevated in the studied groups compared to control group. This elevation was significantly decreased in treated groups compared to RA group. There was no significant difference in Anti-CCP levels between Oil and M1 group but there was significant decrease in M2 group compared to M1 group. Anti$\mathrm{CCP}$ and RF levels were significantly decreased in groups treated with combination of MTX and S.O compared to group treated with S.O only or MTX only and the decrease in Oil+M2 group was significantlymore than Oil+M1 group as shown in figure (1).

The levels of TNF- $\alpha$, IL- 6 and NO were significantly augmented in all groups compared to control group. However, this elevation in these inflammatory biomarkers was decreased significantly in treated groups compared to RA group. The levels of TNF- $\alpha$, IL- 6 were significantly decreased in groups treated with combination of S.O and MTX compared to group treated with S.O only or MTX only and the decrease in S.O+M2 group was significantly more than S.O+M1 group. NO levels were significantly decreased in M2 group comparing to M1 group. In all studied groups, the levels of IL-10 were significantly declined comparing to control group. This reduction was significantly increased in treated groups compared to RA group. The levels of IL-10 were significantly amplified in groups treated with combination of MTX and S.O compared to group treated with S.O only or MTX only and the increase in S.O+M2 group was significantly more than S.O+M1 group as shown in figure (2).

In RA group, the levels of MMP-3 were significantly elevated while IGF-1 were significantly decreased compared to control group. The decreasing effect of S.O and MTX on MMP-3 were recorded in the following order of: $\mathrm{S} . \mathrm{O}+\mathrm{M} 2>\mathrm{S} . \mathrm{O}+\mathrm{M} 1>\mathrm{M} 2 \geq \mathrm{S} . \mathrm{O}>\mathrm{M} 1$. The increase inIGF-1 levels by different treatment were recorded as in the following order:S.O+M2>S.O+M1 $>\mathrm{M} 2>\mathrm{S} . \mathrm{O} \geq \mathrm{M} 1$ as presented in figure (3).

The levels of liver enzymes and T.B were significantly increased in RA group compared to control group, the decreasing effect of S.O and MTX were recorded in the following order:S.O $\geq$ S.O+M1 $>$ S.O+M2 $>\mathrm{M} 1>\mathrm{M} 2$. T.P levels were significantly decreased in RA group compared to control group, the increasing effect of S.O and MTX on T.P were increased in the order of: $\mathrm{S} . \mathrm{O} \geq \mathrm{S} . \mathrm{O}+\mathrm{M} 1 \geq \mathrm{S} . \mathrm{O}+\mathrm{M} 2>\mathrm{M} 1>$ M2 as shown in figures $(4,5)$. 
TAC and GSH levels were significantly declined in the studied groups compared to control group and group treated with S.O only. This reduction was significantly improved in treated groups compared to RA group. The levels of TAC were significantly increased in groups treated with S.O only or combination with MTX than taken MTX only. On the other hand the levels of MDA were significantly increased in the studied groups compared to control and group treated with S.O only. Comparing to RA group, this elevation was significantly increased in groups treated with methotrexate. MDA levels were significantly decreased in groups treated with S.O only or in combination with MTX than taken MTX only as presented in figure (6).

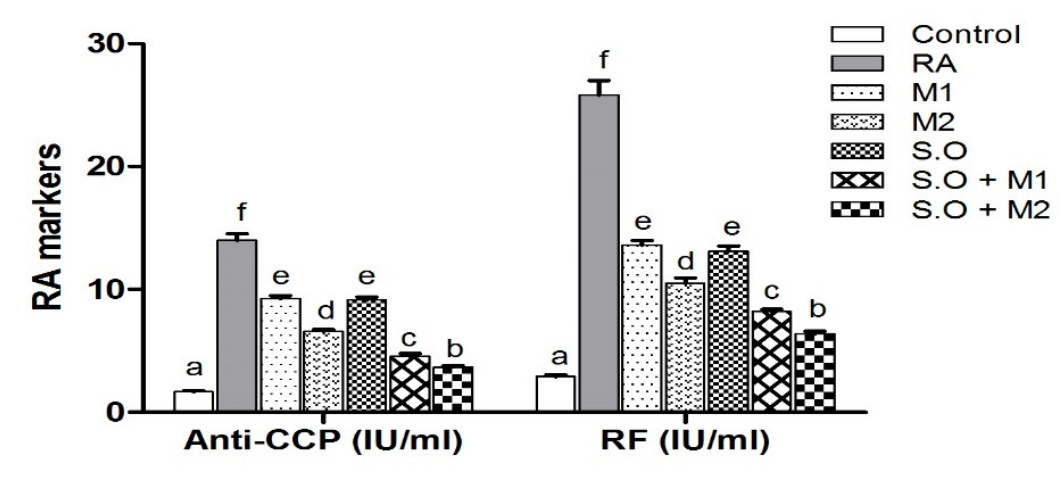

Figure (1): Paw edema, Anti-CCP and RF levels in the studied groups Values presented as mean \pm S.E.Anti-CCP: anti-cyclic citrullinated peptide antibody, RF: rheumatoid factor.Different small letters indicate significant difference between groups at $\mathrm{P}<$ 0.05 . 


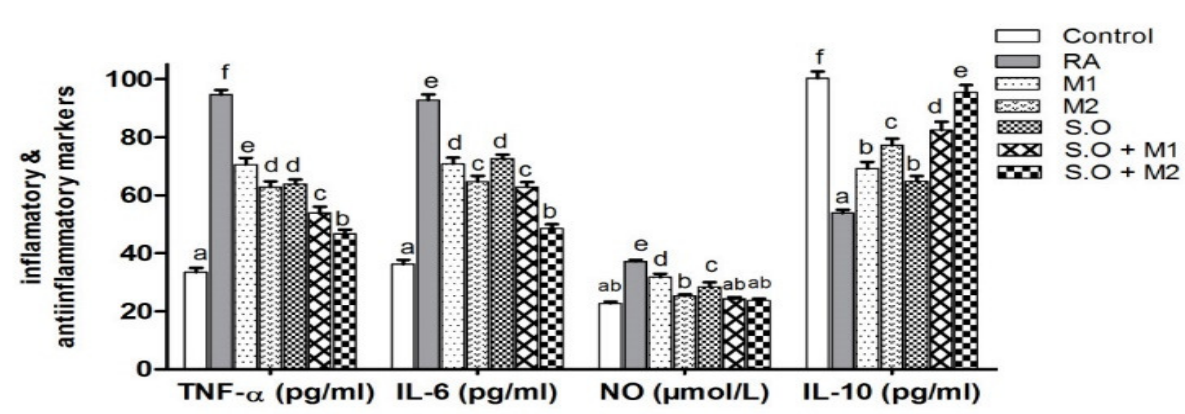

Figure (2): Effect of different treatment on TNF- $\alpha$, IL-6, NO and IL-10 levels Values presented as mean \pm S.E. TNF- $\alpha$ : tumor necrosis factor $\alpha$, IL-6: interleukin 6 , NO: nitric oxide, IL-10: interleukin 10. Different small letters indicate significant difference between groups at $\mathrm{P}<0.05$.

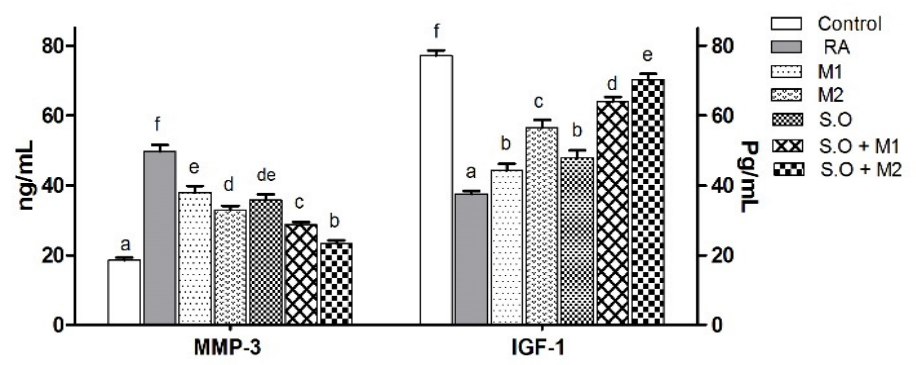

Figure (3): Effect of different treatment on MMP-3 and IGF-1 levels

Values presented as mean \pm S.E. MMP-3: matrix metalloproteinase-3, IGF-1: insulin-like growth factor-1. Different small letters indicate significant difference between groups at $\mathrm{P}<$ 0.05 .

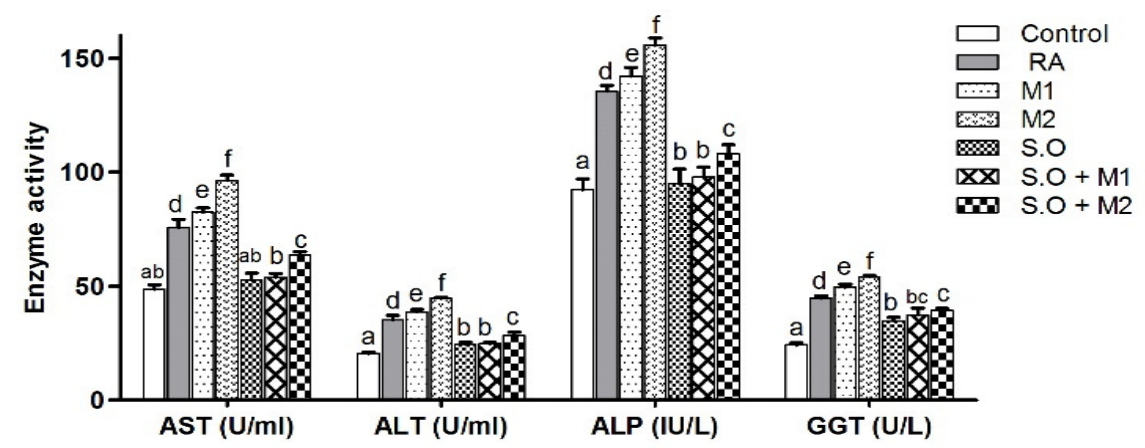

Figure (4): Effect of different treatment on liver function testes

Values presented as mean \pm S.E. ALT: alanine transaminase, AST: aspartate transaminase, ALP: alkaline phosphatase, GGT: $\gamma_{\text {-glutamyltransferase. Different small letters indicate }}$ significant difference between groups at $\mathrm{P}<0.05$. 


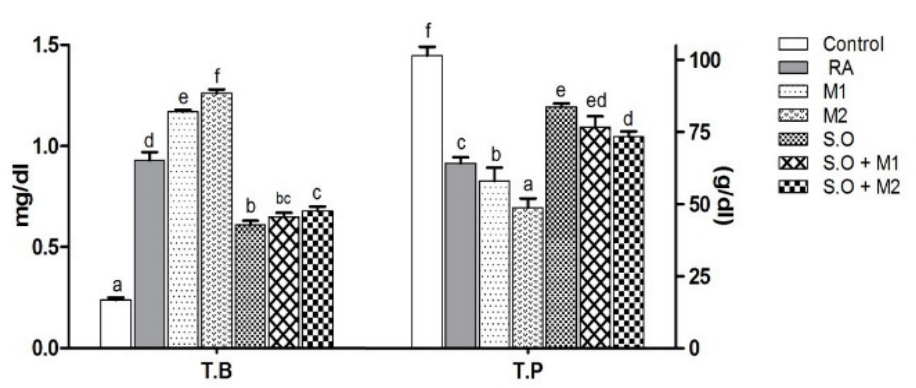

Figure (5): Effect of different treatment on T.B and T.P levels

Values presented as mean \pm S.E. T.B: total bilirubin, T.P: total proteins. Different small letters indicate significant difference between groups at $\mathrm{P}<0.05$.

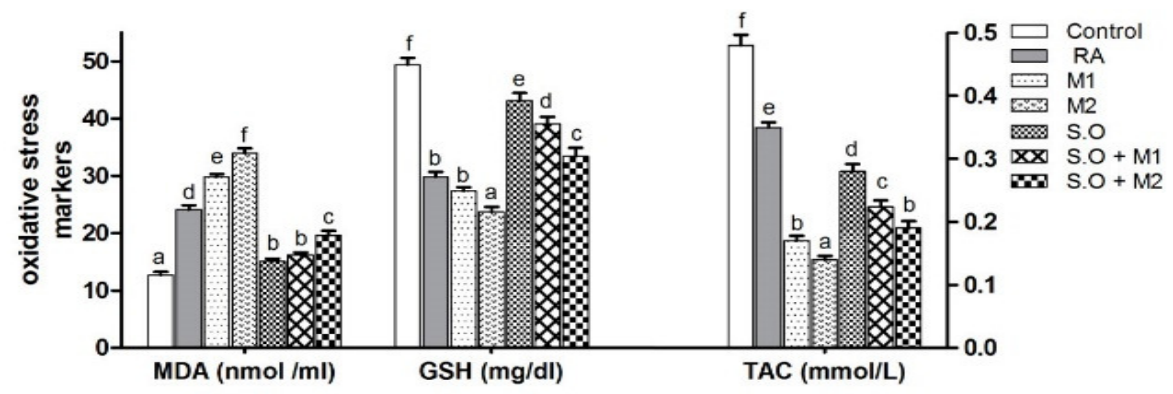

Figure (6): TAC, GSH and MDA levels in the studied groups

Values presented as mean \pm S.E. TAC: total antioxidant capacity, GSH: reduced glutathione, MDA:malondialdehyde.Different small letters indicate significant difference between groups at $\mathrm{P}<0.05$.

\section{DISCUSSION}

The present study aimed to investigate whether the combined therapy of sesame oil with MTX therapeutic dose can ameliorate the hepatotoxicity of MTX, and whether the combined therapy of S.O with MTX sub-therapeutic dose can provide an effective treatment for RA.

The paw edema,RF and anti-CCP antibody were significantly reduced with combined therapy of MTX with sesame oil so the combination was more effective than MTX mono-therapy. It may be pointed out the synergistic anti-arthritic effect of sesame oil with MTX. These results were consistent with Monteiro et al., (2014)who showed that the sesame oil can prevent pleural exudate formation and the leucocyte migration that confirming the anti-inflammatory activity of 
the oil. This effect may be due to the presence of lignans as sesamin which known to have action against pain and inflammation.

The immunosuppressive and an anti-inflammatory cytokine effect of IL-10 plays a key role in the treatment potential therapeutic in several autoimmune diseases such as Crohn's, psoriasis disease and rheumatoid arthritis, according to clinical observation (Bilivogui et al., 2015).

The results showed that MTX andsesame oil were associated with immunosuppression of pro-inflammatory mediators (TNF- $\alpha$, IL-6 and NO) and enhancement the production of IL-10. However, thecurative effect of MTX was associated with hepatotoxic response and free radical formation. Our results are consistent with previous reports of MTX-mediated the development of hepatic fibrosis (Yeo et al., 2013).Selvarajan et al., (2015) confirmed the effect of sesame oil as anti-inflammatory and antioxidant by mechanism involved inhibiting the levels of TNF- $\alpha$ and IL-6 in-vivo at different concentrations.Moreover, Wei et al., ( 2015) reported that MTX has effect on inhibitting the processesof inflammation and destruction accompained to RA by preventing the formation of immunoglobulins and diverse inflammatory cytokines (IL-6 and TNF- $\alpha$ ). Narasimhulu et al., (2015) demonstrated the sesame oil anti-inflammatory characters as evidenced from significant inhibition of plasma inflammatory cytokines, such as IL-1 $\alpha$, IL-6. Furthermore, recent study proved the anti-inflamatory potential of sesame oil and recommended sesame oil to be used in complementary therapy for pain management due to affordable, easy to use and lack of side effects (Shamloo et al., 2015).

MMP-3 plays a pivotal role in the destruction of bone and degradation of various components of cartilage in RA (Galil et al., 2016). IGF-1 inhibits cytokine-stimulated degradation of proteoglycans directly in normal cartilage in-vitro. These anabolic and protecting properties make IGF-1 an obvious candidate for a major role in cartilage repair (Genre et al., 2014). In the current study, the obtained resultsindicated the significant elevation in MMP-3 in arthritic group as compared with normal control group. This elevation was significantly decreased in treated group with S.O alone or with both doses of MTX. These results were in accordance with Yoshiharaa et al., (2010) who reported that serum MMP-3 level was significantly higher in RA group compared to the healthy control.Shiozawa et al., (2016) found that half of rheumatoid patients treated with MTX monotherapy for 3 
years exhibited structural remission, and this outcome can be predicted at the onset by lower serum MMP-3. Also, our study was supported by Wei et al., (2015) who reported that MTX suppresses MMP-3 level in treatment of RA.In the current study, IGF-1 decreased significantly in arthritic group as compared with normal control group. This reduction was significantly elevated in treated group with S.O or both doses of MTX. These results were in accordance with Baker $\boldsymbol{e t}$ al., (2016) who found lower IGF-1 levels in RA patients with greater disease activity and severity. In the current study, MTX therapy caused deterioration in liver function as there was a significant elevation in liver enzymes and total billirubin serum levels accompanied with significant deplelion in the serum total protein. The obtained results demonstrated the hepatoprotective effect of sesame oil which revealed that the significant decrease in serum liver enzymes in arthritic rats treated with combined therapy of oil and MTX.

The recorded study was supported by Patel et al., (2014)and Elbrabary et al., (2016)who reported a significant increase in liver enzymesand decrease in serum total protein in the MTX group which attributed to the damaged structural integrity of liver possibly by oxidative stress and lipid peroxidation.

Also,Chiang et al., (2014) reported that sesaminhas antioxidant and anti-inflammatory action that significantly declined the serum levels of AST, ALT, and CRP in the rat model. This finding could be due to the existence of sesamin which is the most abundant lignan in sesame oil (Huang, 2014).Sesamin has little antioxidant activity but in liver, it can be metabolized into several catechol forms. These metabolites have potent capability to scavenge superoxide radicals (Yasuda and Sakaki, 2012). The obtained results confirmed the usefulness of sesame oil in preventing liver injury developed by MTX-associated oxidative damage.

Antioxidant status and oxidative stressare important factors that exhibited important roles in RA pathogenesis(Dixit et al., 2015). RA is characterized by disequilibrium in the oxidant/antioxidant homeostasis as a result of oxidative stress, chronic inflammation, and activation of metalloproteinase and destruction of matrix(Chimenti et al., 2015). Recent studies revealed that the lipid peroxidation and oxidative stress have a vital role in the liver toxicity of MTX. Excessive formation of reactive oxygen species is one mechanism involved in the starting of liver cell damage, led to impairment of 
dynamic equilibrium in homeostatic condition, thus resulting in intracellular oxidative stress (Singh et al., 2016a). In the present study,MTX monotherapy enhanced significant oxidative stress (significant decreased in TAC and GSH levels) acomppined with enhanced lipid peroxidation (marked elevation in MDA level).The obtained data revealed a profound hepatoprotective effect of sesame oil accompanied by significant increase in TAC and GSH serum levels and significant reduction of MDAserum level, indicating reduced reactive oxygen species formation which is considered as one of the mechanisms by which the hepatotoxic effect of MTX was mediated.

MTX has been reported to increase lipid peroxidation and reduce antioxidant capacity (Dhanesha et al., 2015).Akbulut et al., (2014)andElbrabary et al., (2016) found that MXT administration increases the level of MDA and causes decrease in glutathione levels andsuper oxide dismutase activities in liver.Haghighian et al., (2014) demonstrated a positive effect of sesame seed in decreasing MDA in patients with osteoarthritis and indicated the fact that sesame seed might be helpful to reduce oxidative stress in osteoarthritic patients.In agreement withVasiljevic et al., (2016), the current study suggested that the potential protectiveeffect of sesame oil was contributed by its capability to increase GSH biosynthesis and strength serum total antioxidant capacity to counteract the overproduction of free radical efficiently and to protect the membrane lipids from peroxidation and to combat oxidative stress.

In conclusion, combined therapy of MTX with sesame oil may lead to synergistic anti-arthritic action with fewer side effects of MTX on liver.

\section{REFERENCES}

Akbulut S, Elbe H, Eris C, Dogan Z, Toprak G, Otan E, Erdemli E and Turkoz Y (2014): Cytoprotective effects of amifostine, ascorbic acid and $\mathrm{N}$-acetylcysteine against methotrexate-induced hepatotoxicity in rats; World J Gastroenterol; 20(29): 10158-65.

Ayana NG (2015): Status of Production and Marketing of Ethiopian Sesame Seeds (Sesamumindicum L.): A Review. Agricultural and Biological Sciences Journal; 1 (5): 217-23. 
Baker JF, Von Feldt JM, Mostoufi-Moab S, Kim W, Taratuta E and Leonard MB (2016): Insulin-like Growth Factor 1 and Adiponectin and Associations with Muscle Deficits, Disease Characteristics, and Treatments in Rheumatoid Arthritis;JRheumatol; 42(11): 2038-45.

Banji D, Pinnapureddy J, Banji OJ, Saidulu A andHayath MS (2011): Synergistic activity of curcumin with methotrexate in ameliorating Freund's Complete Adjuvant induced arthritis with reduced hepatotoxicity in experimental animals. Eur J Pharmacol.; 668(1-2): 293-8.

Belfield A and Goldberg DM (1971):Colorimetric determination of serum acid phosphatase activity using adenosine 3'-monophosphate as substrate.Enzyme;24(6): 493-500.

Beutler E, Duron O and Kelly MB (1963):Improved method for the determination of blood glutathione; J Lab Clin. Med. 61,882-8.

Bilivogui KK, Kourouma A, liping C, Yi LZ and Wu X (2015): Interleukin-10 and Receptors in Treatment Rheumatoid Arthritis; IOSR Journal of Pharmacy and Biological Sciences; 10(3): 113-8.

Bizzaro N, Mazzanti G, Tonutti E, Villalta D and Tozzoli $R$ (2001): Diagnostic Accuracy of the Anti-Citrulline Antibody Assay for Rheumatoid Arthritis. Clinical Chemistry; 47(6): 1089-93.

Borashan FA, Ilkhanipoor M, Hashemi M and Farrokhi F (2009): Investigation the effects of curcumin on serum hepatic enzymes activity in a rheumatoid arthritis model. Electron. J. Biotechnol; 4: 129-33.

Castro-Villegas C, Pérez-Sánchez C, Escudero A, Filipescu I, Verdu M, et al. (2015): Circulating miRNAs as potential biomarkers of therapy effectiveness in rheumatoid arthritis patients treated with anti-TNF $\alpha$. Arthritis Research \& Therapy; 17: 49- 63.

Chiang HM, Chang H, Yao PW, Chen YS, Jeng KC, Wang JS and Hou CW (2014): Sesamin reduces acute hepatic injury induced by lead coupled with lipopolysaccharide. J Chin Med Assoc; 77: 227-33.

Chimenti MS, Triggianese P, Conigliaro P, Candi E, Melino G and Perricone $\mathbf{R}$ (2015): The interplay between inflammation and metabolism in rheumatoid arthritis; Cell Death Dis.; 6(9): e1887.

Dhanesha M, Singh K, Bhori $M$ and Marar T (2015): Impact Of Antioxidant Supplementation On Toxicity Of Methotrexate: An In Vitro Study On Erythrocytes Using Vitamin E; Asian J Pharm Clin Res,; 8(3): 339-43. 
Dixit A, Dhasmana DC, Kalra V and Gupta P (2015):Plasma Lipid Peroxidation Levels and Erythrocyte Superoxide Dismutase Activity in Patients with RA: The Relationship with Disease Activity Scores. Research Journal of Pharmaceutical, Biological and Chemical Sciences; 6(5): 111-8.

Elbarbary N, Ismail E AR, Farahat RK and EL-Hamamsy M (2016): $\omega-3$ fatty acids as an adjuvant therapy ameliorates methotrexate-induced hepatotoaxicity in children and adolescents with acute lymphoblastic leukemia: Arandomized placebo-controlled study; Nutrition; 32: 41-7.

Ernst E, Espersen GT, Andersen MV and Grunnet N (1988): RFclasses (IgM, IgG, IgA) in a group of highly active RA- patients in relation to disease activity and treatment. Scand. J. Rheumatol. Suppl.; 75: 250-5.

Galil SMA, El-Shafey AM, Hagrass HA, Fawzy F and EI Sammak A (2016): Baseline serum level of matrix metalloproteinase- 3 as a biomarker of progressive joint damage in rheumatoid arthritis patients. International Journal of Rheumatic Diseases; 19(4):377-84.

Genre F, López-Mejías R, Rueda-Gotor J, Miranda-Filloy J A, Ubilla B, Villar-Bonet A, et al. (2014): IGF-1 and ADMA Levels Are Inversely Correlated in Nondiabetic Ankylosing Spondylitis Patients Undergoing Anti-TNF-Alpha Therapy; BioMed Research International; 2014:671061.

Gornal AC, Bardawill CJ and David MM (1949): Determination of serum proteins by means of the biuret reaction. J. Biol.Chem.;177(2): 751-66.

Haghighian MK, Alipoor B, Sadat BE, Mahdavi AM, Moghaddam A and Vatankhah AM (2014): Effects of sesame seed supplementation on lipid profile and oxidative stress biomarkers in patients with knee osteoarthritis. Health PromotPerspect; 4(1):90-7.

Heersink W, Hafkenscheid JCM, Siepel H, Van der venjongekryg J, Dijt CCM (1980):Temperature-convertingfactors for enzymes:comparison of methods. Enzyem; 25: 333-41.

Huang YS (2014): Open, sesame! The gateway to mitigate hepatic injury using sesamin. J Chin Med Assoc; 77(5): 219-20.

Koracevic D, Koracevic G, Djordjevic V, Andrejevic S and CosicV (2001): Method for the measurement of antioxidant activity in human fluids. J ClinPathol; 54: 356-61. 
Maja BĆ, Oscar FC, Marjonne CW, Martijn C, Antonius HM, Jan Maarten van and Nico MW (2013): Prevalence of methotrexate intolerance in rheumatoid arthritis and psoriati arthritis. BulatovićĆalasan et al. Arthritis Research \& Therapy; 15: R217.

Monteiro EM, Chibli LA, Yamamoto CH, Pereira MC, Vilela FM, Rodarte MP, Pinto MA, et al. (2014): Antinociceptive and AntiInflammatory Activities of the Sesame Oil and Sesamin; Nutrients;12 (6): 1931-44.

Montgomery HAC and Dymock JF (1961): The determination of nitrate in water. Analyst; 86: 414-6.

Narasimhulu CA, Selvarajan K, Litvinov D and Parthasarathy S (2015): Anti-atherosclerotic and anti-inflammatory actions of sesame oil. J Med Food; 18 (1): 11-20.

Ohkawa H, Ohishi W and Yagi K (1979): Assay for lipid peroxides in animal tissues by thiobarbituric acid reaction. Anal. Biochem Jun; 95(2): 351-8.

Patel NN, Ghodasara DJ, Pandey S, Ghodasara PD, Khorajiya JH, Joshi BP and Dave CJ (2014): Subacutetoxicopathological studies of methotrexate in Wistar rats ; Veterinary World; 7 (7): 48995.

Reitman A and Frankel S (1957): A colorimetric method for the determination of serum glutamic oxalacetic and glutamic pyruvic transaminases. Amer J. Clin. Path.; 28(1): 56-63.

Selvarajan K, Narasimhulu CA, Bapputty $R$ and Parthasarathy $S$ (2015): Anti-inflammatory and antioxidant activities of the nonlipid (aqueous) components of sesame oil: potential use in atherosclerosis. $\mathrm{J}$ Med Food; 18(4): 393-402.

Shamloo MB, Nasiri M, Dabirian A, Bakhtiyari A, Mojab F and Alavi MH (2015): The Effects of Topical Sesame (Sesamumindicum) Oil on Pain Severity and Amount of Received Non-Steroid AntiInflammatory Drugs in Patients With Upper or Lower Extremities Trauma; Anesth Pain Med.; 5(3): e25085.

Sharma $P$ and Scott DGI (2015): Optimizing Methotrexate Treatment in Rheumatoid Arthritis: The Case for Subcutaneous Methotrexate Prior to Biologics. Current Opinion Drugs; 75 (17): 1953-56.

Shiozawa K, Yamane T, Murata M, Yoshihara R, Tsumiyama K, Imura $S$ and Shiozawa $S$ (2016): MMP-3 as a predictor for structural 
remission in RA patients treated with MTX monotherapy; Arthritis Research \& Therapy; 18:55.

Singh D, Cho WC and Upadhyay G (2016a): Drug-Induced Liver Toxicity and Prevention by Herbal Antioxidants: An Overview. Front. Physiol.; 6:363.

Singh JA, Saag KG, Bridges SL, Akl EA, Bannuru RR, Sullivan MC, Vaysbrot E, McNaughton C, Osani M, Shmerling RH, et al. (2016b): American College of Rheumatology Guideline for the Treatment of Rheumatoid Arthritis. Arthritis Rheumatol; 68(1): 1-26.

Sotnikova R1, Ponist S, Navarova J, Mihalova D, Tomekova V, Strosova M and Bauerova K (2009): Effects of sesame oil in the model of adjuvant arthritis NeuroEndocrinolLett.; 30 (1): 22-4.

Vasiljevic D, Veselinovic M, Jovanovic M, Jeremic N, Arsic A, Vucic V, Lucic-Tomic A, Zivanovic S, Djuric D and Jakovljevic V (2016): Evaluation of the effects of different supplementation on oxidative status in patients with rheumatoid arthritis. ClinRheumatol;35(8):1909-15.

Water $M$ and Gerade $H$ (1970): A colorimetric method for determination bilirubin in serum and plasma. Micro Chem J.; 15: 2316.

Wei Y, Sun X, Hua M, Tan W, Wang F and Zhang M (2015): Inhibitory Effect of a Novel Antirheumatic Drug T-614 on the IL-6Induced RANKL/OPG, IL-17, and MMP-3 Expression in Synovial Fibroblasts from Rheumatoid Arthritis Patients; Bio Med Research International;2015, Article ID 214683, 8 pages.

Xu F, Li Y, Li S, Ma Y, Zhao N, Liu Y, Qian N, Zhao H and Li Y (2014): Complete Freund's adjuvante induced acute inflammatory pain could be attenuated by triptolide via inhibiting spinal glia activation in rats. Journal of Surgical Research; 188: 174-82.

Yasuda K and Sakaki T (2012): How is sesaminmetabolised in the human liver to show its biological effects? Expert Opin Drug MetabToxicol; 8: 93-102.

Yeo CM, Chong VH, Earnest A and Yang WL (2013): Prevalence and risk factors of methotrexate hepatoxicity in Asian patients with psoriasis; World Journal of Hepatology; 5(5): 275-80.

Yoshiharaa $Y$, Nakamurab $\mathrm{H}$, Obatac $\mathrm{K}$, Yamadad $\mathrm{H}$, Hayakawae T, Fujikawaa $K$ and Okadab $Y$ (2010): Matrix metalloproteinases and tissue inhibitors of metalloproteinases in 
synovial fluids from patients with rheumatoid arthritis or osteoarthritis. Ann Rheum Dis.; 59(6): 455-61.

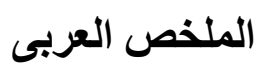

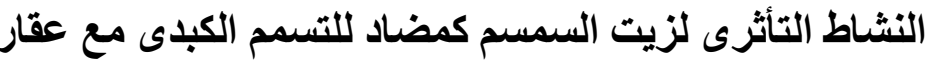

الميثوتريكسيات فى علاج الالتهاب الروماتويدى المفصلسالمستحدثفى فئران

$$
\text { التجارب }
$$

زينب يوسف على-1حنان عبد الموجود عطية-روؤوف محمدالألاوى- 1شيماء محمد

قالزم الكيمياء الحيوية ـ الهيئة القومية للرقابة و البحوث الدوائية' كلية الصيدلة (بنات)جامعة

يعدالميثوتريكسات الخيار الأول في علاج الروماتويد المفصلي إلا أنه يؤدى إلى حدوث

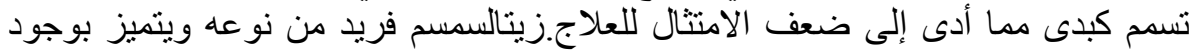

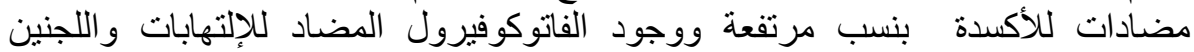

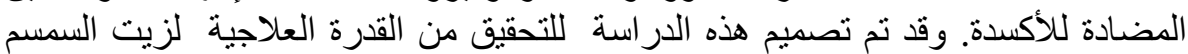

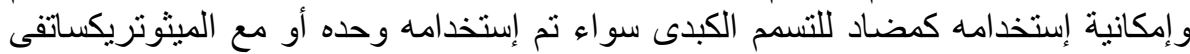

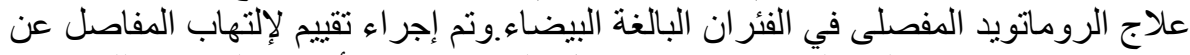

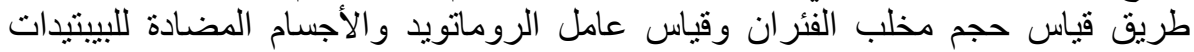

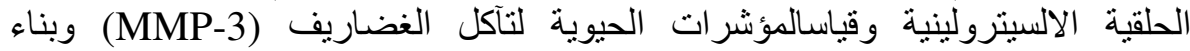
الغضاريف (IGF-1) و أيضا قياس المؤشرات المؤدية للالتهابات (TNF-

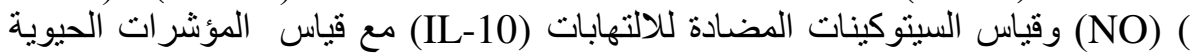

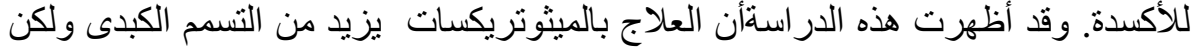

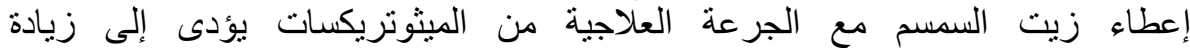

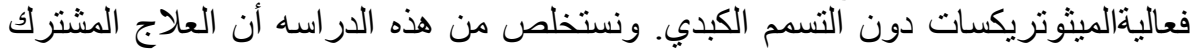

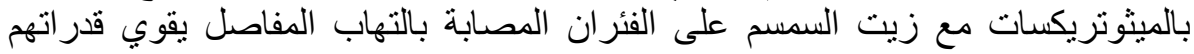

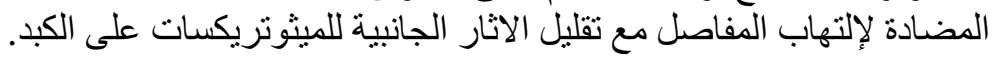

